\title{
Corpos Striped: sujeição à insurgência simbiótica
}

\author{
Striped Bodies: \\ Subjection to Symbiotic Insurgency
}

\author{
Corpos Striped: \\ sujeción a la insurgencia simbiótica
}

Rafael Coutinho ${ }^{1}$

http://dx.doi.org/10.22409/poiesis.1830.55-78

\begin{abstract}
RESUMO: Corpos Striped constitui-se em uma produção seriada de nove (9) desenhos realizados pelo pesquisador e artista Rafael Scheibe Coutinho, a qual reflexiona aspectos devastadores presentes na sociedade contemporânea, sobretudo apregoando a figura da mulher como objeto de desejo e consumo de maneira abjeta. Para tanto, adiciona-se a esta figura uma relação insurgente com a criatura polvo, que se sobrepõe à mulher fazendo às vezes de uma vasta e repulsante cabeleira. $O$ polvo assume metaforicamente o peso grotesco imposto pela sociedade como uma força que sufoca e transgride a feminilidade, envolvendo-a por meio de uma relação simbiótica e camuflando-se de forma capilar, transformando-a na representatividade da medusa contemporânea.
\end{abstract}

PALAVRAS-CHAVE: artes visuais; desenho contemporâneo; simbiose; crítica social

\footnotetext{
${ }^{1}$ Rafael Scheibe Coutinho é artista visual e professor. Doutorando inserido na linha de pesquisa Poéticas Visuais e Processos de Criação no Instituto de Artes da Unicamp, é Mestre em Artes Visuais (IA-UNICAMP) e Especialista em Artes Visuais, Intermeios e Educação (IA-UNICAMP). E-mail: coutinho.rafael@gmail.com
} 


\begin{abstract}
Striped Bodies is a serial production of nine (9) drawings by researcher and artist Rafael Scheibe Coutinho, which reflects devastating aspects present in contemporary society, especially proclaiming the figure of woman as object of desire and consumption in an abject way. For this, an insurgent relationship with the octopus creature is added to this figure, which overlaps with the woman sometimes making a vast and repulsive wig. The octopus assumes metaphorically the grotesque weight imposed by society as a force that suffocates and transgresses femininity, involving it through a symbiotic relationship and camouflaging itself capillary, transforming it into the representation of the contemporary medusa.
\end{abstract}

KEYWORDS: visual arts; contemporary drawing; symbiosis; social criticism

RESUMEN: Corpos Striped se constituye en una producción seriada de nueve (9) dibujos realizados por el investigador y artista Rafael Scheibe Coutinho, la cual refleja aspectos devastadores presentes en la sociedad contemporánea, sobre todo pregonando la figura de la mujer como objeto de deseo y consumo de manera abyecta. Para ello, se añade a esta figura una relación insurgente con la criatura pulpos, que se superpone a la mujer haciendo a veces de una vasta y repulsante cabellera. El pulpo asume metafóricamente el peso grotesco impuesto por la sociedad como una fuerza que sofoca y transgrede la feminidad, envolviéndola por medio de una relación simbiótica y camuflando de forma capilar, transformándola en la representatividad de la medusa contemporánea.

PALABRAS CLAVE: artes visuales; diseño contemporáneo; simbiosis; crítica social

Como citar: COUTINHO, Rafael. Corpos Striped: sujeição à insurgência simbiótica. Poiésis, Niterói, v. 18, n. 30, p. 55-78, dez. 2017. doi: http://dx.doi.org/10.22409/poiesis.1830.55-78

Poiésis, Niterói, v. 18, n. 30, dez. 2017. 


\section{Corpos Striped: sujeição à insurgência simbiótica}

Striped, palavra de origem inglesa que em uma tradução direta para o português seria algo como "listrado", inserido no contexto de minha produção visual intitulada Corpos Striped, angaria um jogo de palavras atraídas pela fonética e também pelo tratamento visual estético atribuído aos desenhos. Portanto, dentro das possibilidades fonéticas da língua portuguesa, facilmente poderíamos obter algo como "Corpos Estripados" ou "Corpos Estuprados". Veremos adiante que tal polissemia fonética não está restringida à sonoridade, mas ganha força na significação das palavras originadas por esta livre associação. Também, não há como ignorar a expressão inglesa conjunta, strip-tease, em alusão ao caráter sensual das figuras.

No que diz respeito ao visual, tal joguete de palavras é potencializado quando se observa as listras irregulares e dilacerantes que cortam os corpos femininos, sobrepondo-se em transparência por meio da aguada de tinta aquarela e também em maior agressividade 
pelas manchas negras que meticulosamente foram "desenhadas" para sobrepor os olhos ou a boca das figuras em atitude de censura: uma repreensão traduzida em vandalismo contra o delineamento.

Além do corpo feminino, em cada desenho é possível notar um corpo estranho que insurge sobre cada uma delas, o qual sobrepõem-se às suas cabeças, assumindo assim o lugar dos cabelos do mesmo modo que dois seres diferentes estabelecem uma relação simbiótica' na natureza. Deste modo, a substituição por equivalência da cabeleira por este corpo estranho, que é o polvo, acarreta uma alusão à górgona medusa, já que os tentáculos do cefalópode também remetem imageticamente às esguias e horripilantes serpentes, as quais são inerentes à figura mitológica.

Portanto, sugiro, com esta série de desenhos, a figuração de "medusas contemporâneas" que, assim como a figura mitológica original, são desprezadas e desprezíveis, convertendo-se em mulheres ocultadas na sociedade, materializadas como produto e posteriormente descartadas. A "coisificação" da mulher a rebaixa como um simples objeto de desejo que pode ser facilmente descartável, após servir aos propósitos de quem a usou.

Destarte, se na visão clássica os que contemplavam a medusa "original" petrificavam-se, os que hoje possuem a ousadia de fitar os olhos das "medusas contemporâneas" são petrificados pela cauterização dos sentimentos mais nobres para dar vazão ao asco impelido por elas. Àqueles que optam por envolver-se com elas são marcados e envoltos por suas serpentes tentaculares. Assim, como a górgona original pertence ao mundo abissal, habitante das profundezas do mar, na contemporaneidade elas habitam o submundo, escondidas nos recônditos, sofrendo as agruras de uma sociedade "civilizada", transformando-se em objeto abjeto, conceito este que, a partir de Hal Foster, Marta Luiza Strambi pontua como

[...] uma substância fantasmática que não é alheia ao sujeito, é intima com ele; e é esta super-proximidade que produz o pânico no sujeito. Sendo assim, 0 abjeto afeta a fragilidade de nossos limites, a fragilidade da distinção especial entre as coisas em nosso interior eno exterior. (STRAMBI, 2008).

Poiésis, Niterói, v. 18, n. 30, dez. 2017. 
O abjeto é algo intrínseco a estas mulheres, fragilizadas por uma sociedade pautada por falsos moralismos, calcada no egocentrismo e em pré-julgamentos. São mulheres sem identidade, massificadas, encontradas em qualquer canto. A ausência da identidade e, por conseguinte, da individualidade, as torna invisíveis dentro do sistema. São vítimas de um processo simbiótico com a criatura polvo: camufladas, omitidas, abafadas, envoltas, amarradas, sufocadas. Perderam a voz e agora a linha que separa o interior e o exterior tornou-se tênue demais. Dentro e fora delas, criou-se um mundo abissal, enegrecido, no qual apenas se pode tatear, sem saber onde pisar e como sair desse estado labiríntico, formado por nós tentaculares.

A série de desenhos Corpos Striped é composta por nove (9) desenhos em grafite com faturas cromáticas atenuadas em aquarela que também servem para trazer um embotamento sobre algumas áreas dos desenhos, reforçando o conceito de ocultamento do indivíduo através de um processo de apagamento de certos contornos. A perda da identidade é reforçada pelos títulos atribuídos aos desenhos, os quais são resumidos a striped e seguidos por uma sequência numérica. Portanto, reforço a ideia de que as moças representadas são massificadas. Metaforicamente são produtos, ou melhor, subprodutos. Converteram-se em objetos que servem ao prazer alheio e posterior descarte com possibilidades de reuso. Ainda que não vejamos suas faces integralmente, elas revelam intensa melancolia, convertendo-se em figuras fantasmáticas que habitam a escuridão, embora os desenhos não sejam escuros. Ao contrário: apresentam-se como faróis que expõem a ferida, a vergonha, o descaso e, enfim, a face lúgubre de uma sociedade inóspita travestida de fantasias.

A fim de suscitar as múltiplas e complexas facetas da sociedade contemporânea, optou-se por utilizar a figura do polvo, a qual ajustou-se com exatidão metafórica representacional. O modo como se apropria, se envolve e gruda, demonstra o poder que a sociedade tem de subjugar e oprimir aqueles que se demonstram "fracos".

Seus tentáculos que se esgueiram e deslizam sobre o corpo com facilidade, tomando a forma do corpo humano, procuram se estabilizar de maneira repressora. Uma das quali- 
dades do polvo é o seu poder de mimetização, por meio de sua eficiente camuflagem, e utiliza-o fazendo uso de sua múltipla configuração formal: contraindo-se e expandindo-se, defende e ataca, aparece e some. Enfim, carregada de um certo misticismo que lhe confere uma capacidade ardilosa, tem por finalidade se esconder e surpreender.

A capacidade que o polvo tem de se apresentar como uma forma instável ou, de acordo com Omar Calabrese (1987), "forma informe", Ihe confere dinamismo e um alto poder de adaptabilidade. Ainda, de acordo com o autor, "[...] forma informe, em resumo, provoca bimodalidade de comportamentos." (CALABRESE, 1987, p. 114, grifo do autor) Essa é a face da sociedade contemporânea: dinâmica em todo o tempo, como parece melhor lhe convir. O monstro contemporâneo possui essa faceta em sua representação imagética. Assim sendo, o polvo não é apenas um animal, mas um monstro que tomou posse das ações humanas em um processo simbiótico.

Proponho com esta reflexão trazer uma análise individualizada de alguns dos desenhos que compõe Corpos Striped e estabelecer diálogos com algumas obras que referenciam a minha proposta. Sendo assim, apresento inicialmente, Striped I (Fig. 1), no qual introduzo uma mulher em meio perfil, de costas nuas voltadas para o espectador, esmaecidas antes mesmo de chegarem ao limite do suporte. Podemos apenas imaginar como são os seus olhos, já que agora se apresenta obstruído por uma mancha negra na direção vertical, a qual toma toda a extensão do rosto sem comprometer o perfil e os seus pálidos lábios. A outra metade do rosto permanece oculta pela penumbra projetada. $O$ desenho se apresenta bem delineado, com pouco espaço para uma subjetividade acerca das figuras de modo que seja possível, sem grande dificuldade, identificar a presença do polvo sobre a cabeça da jovem mulher. A carga simbólica deste, e também dos demais desenhos, está potenciada justamente pela presença insólita do cefalópode sobre a mulher, pois este ocupa um lugar que não é próprio de seu habitat, conferindo uma característica onírica às obras.

A mancha escura, sobreposta à figura, elimina qualquer traço puritano que outrora deveria existir na jovem. De figura imaculada passa a ser manchada, subvertida, censurada,

Poiésis, Niterói, v. 18, n. 30, dez. 2017. 
Fig. 1 - Rafael Coutinho, Striped I, 2015.

grafite e aquarela sobre papel, $21 \times 29,5 \mathrm{~cm}$

(Fonte: Acervo pessoal, Campinas, SP) 
mas sua beleza não é anulada quando os olhos passeiam pelas áreas que foram "preservadas". As pinceladas aguadas que formam uma camada transparente não são suficientes para ocultar o desenho, mas fornecem um aspecto sujo junto à figura pálida. A ocultação parcial e a "sujeira" são uma deterioração proposital; um vandalismo contra a própria obra, realizado com cautela. A mácula negra impede que vejamos um de seus olhos e o outro permanece oculto na sombra da cavidade do polvo. Se não a podemos ver, tampouco ela a nós, todavia ergue-se no alto de sua cabeça um dos olhos do polvo. Se "ela" não vê, alguém vê por ela e, por conseguinte decide por ela, controlando suas ações.

A beleza da figura humana coexiste com a viscosidade repelente da criatura, que a torna igualmente indesejável. Por outro lado, a imagem passa uma expressão ostensiva, luxuosa, sedutora, que camufla o esforço para que reconheçamos, fazendo-nos reconhecer o lado oculto da:

nossa própria "sombra" e sua nefasta atividade. Se pudéssemos ver essa sombra (o lado escuro e tenebroso da nossa natureza) ficaríamos imunizados contra qualquer infecção e contágio moral e intelectual. (JUNG, 2008, p. 105)

Esse é o poder investido sobre a figura metafórica do polvo: um agente inibidor, controlador emergido das gavetas mais obscuras do nosso ser a serem abertas involuntariamente. Portanto, este desenho e os demais inseridos em minha produção apresentam uma carga simbólica análoga às aspirações surrealistas, datadas das primeiras décadas do século $X X$, em que se pode observar o encontro entre a produção visual e os devaneios produzidos pelo fértil e, até então, inexplorado terreno da inconsciência. A tônica desse processo está no fato de atribuir uma relação entre dois ou mais elementos que, a princípio, não se relacionam naquilo que entendemos como realidade, ou melhor, no plano natural. Suas possíveis conexões são oriundas de um onirismo que se alimenta dos vislumbres proporcionados pelos devaneios.

A conexão inusitada entre o polvo e a mulher coloca em xeque o estereótipo da beleza feminina, transformando seus cabelos em algo orgânico, vivo e, ao mesmo tempo, inde-

Poiésis, Niterói, v. 18, n. 30, dez. 2017. 
sejável tal qual uma medusa. O enigmático e protuberante artista Salvador Dalí (19041989) serviu-se da mitológica figura ao compor algumas de suas obras, porém pelo menos em duas delas não atribuiu serpentes à cabeça, mas encontrou um substituto equivalente nas formas dos tentáculos de um animal marinho, a sinuosidade hipnótica e, não obstante, selvagem dos tentáculos sobre a sensual figura feminina (Fig. 2).

Vê-se por parte dos surrealistas uma preponderância na utilização de figuras anamórficas para representar as mitopoéticas do universo inconsciencioso, os quais trazem à luz as profundezas da psique humana e, particularmente, nessa gravura, nota-se que a mulher envolta pela criatura marinha contempla um crânio posto sobre um chão composto por linhas em perspectiva. Ela contempla o abismo humano. Daí o encontro com a morte, com o vanitas. Ninguém que olhe para a medusa pode viver - nem ela mesma diante de seu próprio reflexo.

Striped III (Fig. 3) revela uma figura feminina um pouco para além dos ombros, de costas nuas que abrigam manchas escorridas e esvanecidas verticalmente, como que esvaziando todo o potencial de beleza que agora está oculto. Uma "sujeira visceral" cobre o topo da figura e seus olhos estão bloqueados pelo gestual negro que se tornou contumaz nos desenhos desta série, aspirando violação. A inocência já lhe foi tirada pela selvageria. Assim como a tinta escorre pelo seu corpo nu, sem qualquer tipo de proteção, seus sonhos também se esvaem. A pele que agora o polvo habita é valorizada pela presença de um tentáculo que desce pelas costas e recai sobre o ombro. Sua sinuosidade viscosa, grotesca e escura entra em concordância com a sinuosidade do corpo ereto e pálido.

A relação feminina com o grotesco e a dominância dos tentáculos sobre os corpos para além de um referencial moderno em Dalí remete a um estilo tradicional japonês na realização de gravuras com temática erótica. O Sonho da Mulher do Pescador (Fig. 4) de Katsushika Hokusai (1760-1849) se consolidou como principal exemplo desse estilo. É comum perceber nesse contexto que os tentáculos se convertem em falos que envolvem a figura feminina num misto de dor e prazer. É bem verdade que na obra de Hokusai e de outros artistas ligados ao shunga-e (gravuras eróticas japonesas), isto se dá de maneira 


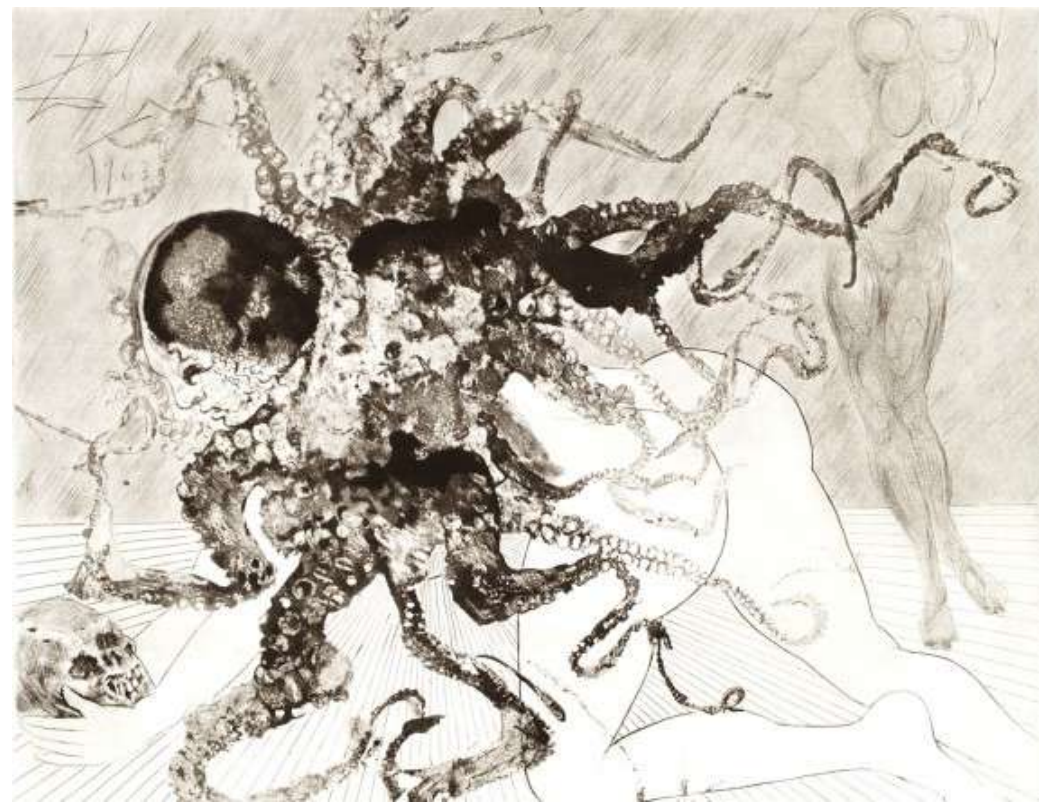

Fig. 2 - Salvador Dalí (1904 - 1989), Medusa da série Mitologia,1963;

ponta seca, $76 \times 56 \mathrm{~cm}$

(Fonte: http://www.christineargilletgallery.com/author/dali/)

Poiésis, Niterói, v. 18, n. 30, dez. 2017. 
Fig. 3 - Rafael Coutinho, Striped III, 2015.

grafite e aquarela sobre papel, $21 \times 29,5 \mathrm{~cm}$

(Fonte: Acervo pessoal, Campinas, SP)

Poiésis, Niterói, v. 18, n. 30, dez. 2017. 


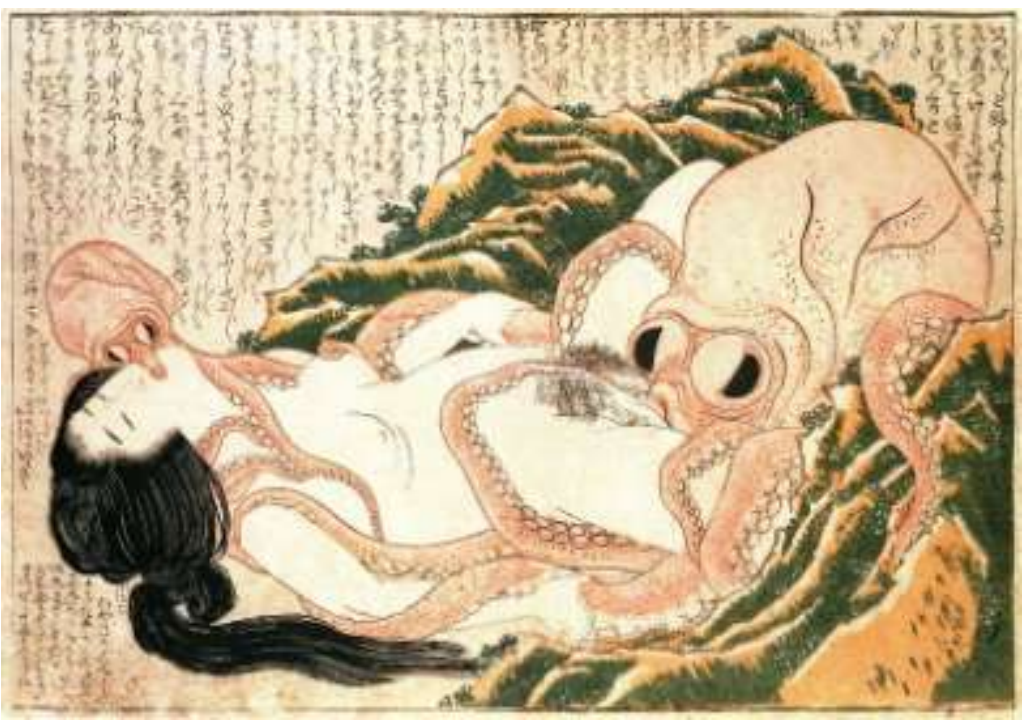

Fig. 4 - Katsushika Hokusai (1760-1849), O Sonho da Mulher do Pescador,1814. xilogravura, $19 \times 27 \mathrm{~cm}$

(Fonte: http://www.wikiart.org/pt/katsushika-hokusai\#supersized-ukiyo-e-223528)

Poiésis, Niterói, v. 18, n. 30, dez. 2017. 
explícita em contraponto à subjetividade da minha produção, em que pese ambas as produções falem de uma relação epidérmica entre o humano e o monstruoso, entre mulher e o polvo, de modo que a multiplicidade de tentáculos sobre o corpo humano caracterize uma dominância a nível corporal, mas, sobretudo à psique. Um dos indícios reside no fato do polvo sempre figurar sobre a cabeça.

Parece inegável o fato de que este desenho Striped IV (Fig. 5) demonstre uma jovem melancólica e solitária. A mão direita no "cabelo" sensualiza um gesto, mas na verdade está presa; o pulso da outra mão apresenta um tentáculo envolto, que mais se assemelha a uma corda. Sem enxergar e com os braços presos, tornou-se refém de sua condição abjeta. Os braços e as pernas cruzadas se traduzem em bloqueio, em um desconforto por estar nesse tipo de situação. Em tom de agressividade a mancha negra corta a figura na altura dos olhos: que é ignorada.

Ainda que as listras sejam transparentes, não são comedidas: cortam o desenho como um todo, assemelhando-se às grades de uma prisão. Portanto fica indubitável a ideia de que a jovem está encarcerada em sua própria vida. Também denotam um aspecto de sujeira em conjunto com as manchas que formam o fundo ao redor da figura feminina, tornando o aspecto do desenho ainda mais esquálido. Bem como neste desenho e, no anterior, as manchas em algumas extremidades confere-lhes um borrão, para que parte da imagem fique desfocada, a exemplo dos tentáculos na extremidade esquerda e parte do seio em Striped III, assim como a mão jogada para o lado esquerdo nessa imagem.

Nota-se também a tentativa de ocultar com uma camada mais aguada a parte superior do desenho, onde se encontra a cabeça do polvo em ambos os desenhos, conferindo-Ihes também este aspecto borrado, como que a criatura fosse uma entidade ou força oculta, que age ardilosamente no intuito de dominá-la sem que seja plenamente descoberto e, por conseguinte, destronado.

A insurgência do cefalópode o caracteriza como ser parasítico, que alastra a sua influência através da sua capacidade expansiva e esguia, conferindo-Ihe uma capacidade ardilosa na tentativa de angariar recursos vitais à sua sobrevivência, tal qual em uma relação simbió- 
tica. Sendo assim, imageticamente, o corpo humano - hospedeiro dessa relação - e, conceitualmente, a psique humana, sucumbe à força prisional de uma sociedade repressora, que sentencia e rotula sem piedade os que são produtos - e, nesse sentido também objetos - resultantes da imanência do mal.

Striped $V$ (Fig. 6) apresenta os traços mais marcados e linhas mais contínuas. Diferentemente das demais, tem o torso coberto por uma blusa espessa e escura que se contrapõe à face pálida e amarelada.

A delimitação da figura acarreta sobriedade e maior robustez, além de apresentar uma aguada mais densa em relação aos desenhos anteriores. O polvo denota austeridade: configura um aspecto mais solidificado, de modo que está mais elevado, sem o caimento gelatinoso que the é peculiar. Novamente os tentáculos recaem sobre o corpo como mechas de cabelo, que aos poucos perdem a definição de contorno e detalhes, pendendo em manchas escuras que escorrem e logo em seguida se dissipam como tripas de um corpo dilacerado. Parece estarmos diante do triunfo da besta.

Diferentemente dos desenhos anteriores, a jovem não está apenas vestida, mas coberta com uma blusa espessa que se mescla às manchas provenientes dos tentáculos, como estampadas sórdidas que revelam a atmosfera dos lugares pelos quais deva ter passado. Sobretudo há graça nos seus lábios. Algo de sublime; uma esperança de redenção. $O$ olhar, de certa forma é atraído a este ponto, devido ao grande contraste entre a sua palidez e delicadeza, em contraponto à agressão com que se apresenta a negrura que corta a figura.

O polvo é um fardo e continua lá: acoplado; preso; subjugando a jovem, tornando-a desprezível, alimentando-se de toda a sua vitalidade, exaurindo-a até que definhe por completo e, talvez, a única coisa que pode remover o parasita é a superação: libertar a consciência; retomar o senso daquilo que constitui o nosso interior e o nosso exterior, ou seja, a recuperação da identidade perdida em meio à escuridão abissal.

Poiésis, Niterói, v. 18, n. 30, dez. 2017. 

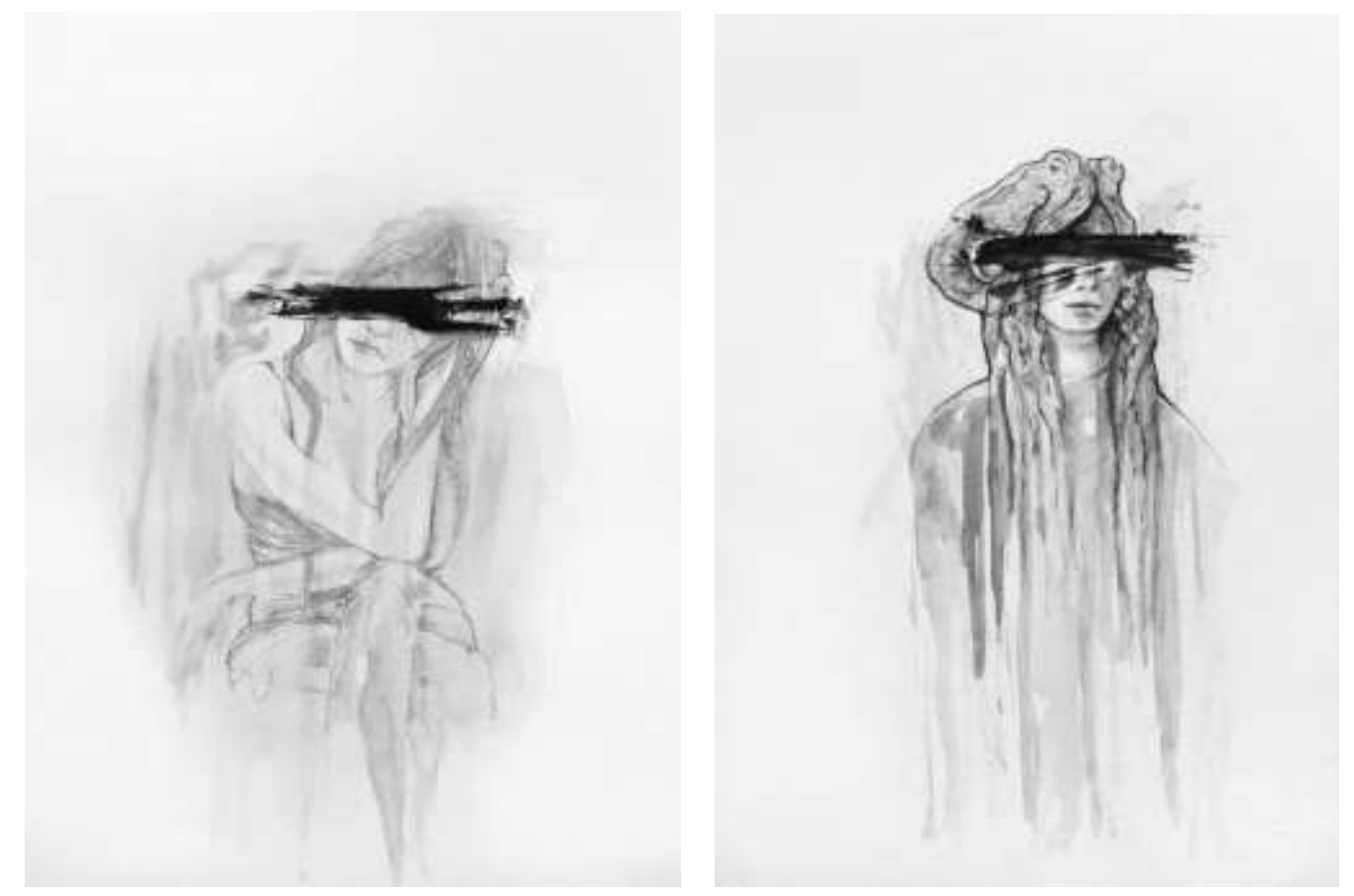

Figs. 5 e 6 - Rafael Coutinho, Striped IV e V, 2015.

grafite e aquarela sobre papel, $21 \times 29,5 \mathrm{~cm}$ (cada)

(Fonte: Acervo pessoal, Campinas, SP) 
Ao regressar à Medusa de Dalí, vemos como o polvo representado em sua gravura se estende como uma explosão: tentáculos abertos em raios subjugam a jovem mulher prostrada e nua, em uma posição sexual e, dessa maneira, não poderia deixar de relacionar com a imagem já vista de Katsushika Hokusai, e realizar um apontamento para outros artistas orientais que exploraram essa conotação sexual entre o cefalópode e a mulher, a exemplo das gravuras Abalone Fishergirl with an Octopus (Fig. 7) e Chiyo-dameshi, ambas de Katsukawa Shunshō (1726-1792) - professor de Hokusai - e também com a gravura Suetsumuhana (A Dyer's Saffron) de Yanagawa Shigenobu (1787-1832).

As gravuras tradicionais japonesas (ukiyo-e), como colocado há pouco, possuem um nicho erótico, denominadas shunga-e. Em particular, estas gravuras nas quais se observam associações entre o polvo e a mulher, carregam consigo a lenda de Taishokanii, na qual uma mergulhadora é perseguida no instante em que retorna à superfície, depois de recuperar uma pedra preciosa de valor inestimável nas profundezas do mar, a qual fora tirada de seu filho pela criatura conhecida como dragão do mar.

Quando perseguida por alguns seres marinhos, dentre eles o dragão, a mulher toma a decisão de abrir o peito com uma adaga e esconder a gema dentro de si a fim de evitar o conflito. Contudo, a mulher é assassinada e, posteriormente o seu filho pôde encontrar a joia dentro de seu corpo que jazia sem vida.

Desta maneira, as gravuras tornaram-se uma paródia, na qual o dragão marinho converte-se em um polvo libidinoso que procura "adentrar" ao corpo da mulher, usando para isso seus tentáculos ludibriosos, que por sua vez se convertem em instrumentos de prazer, com intuito de resgatar o objeto perdido; não tanto pela força (apenas a princípio), mas por meio do entorpecimento.

No Japão, o mergulho em busca de alimento (ostras, lagostas, algas) e pérolas, é uma atividade milenar realizada principalmente por mulheres, conhecidas como "amas".

Contudo, para além das implicações lendárias, discorro para os desdobramentos dessa relação mulher e criatura na produção contemporânea e consequentemente na minha

Poiésis, Niterói, v. 18, n. 30, dez. 2017. 
produção. Essa herança pode ainda ser notada nas gravuras e aquarelas contemporâneas do artista japonês, naturalizado norte-americano, Masami Teraoka (1936-).

Teraoka expõe o seu lado cultural, sob a influência do ukiyo-e, como observado na aquarela Sarah and Writhing Octopus (Fig. 8), no entanto não deixa de recodificar o aspecto tradicional tendo em vista questões que permeiam a contemporaneidade. Teraoka evidencia a inspiração sobre as gravuras no estilo shunga de Shunshō, Shigenobu e Hokusai, todavia nota-se uma mulher que foge ao fenótipo japonês: ela veste um traje de banho atual e possui uma máscara mergulhadora e pés de pato, localizados do lado esquerdo da gravura. Porém, o mais distinto é a presença de algumas embalagens de preservativos na parte inferior da pintura.

Podemos notar também uma expansão desta ideia para o terreno fotográfico pelas lentes do, também, japonês Daikichi Amano (1973-), o qual também parte para uma relação explícita entre a mulher e o polvo (e também com outras demais criaturas), chegando à bizarrice pornográfica, numa mistura de dor e prazer através do grotesco, beirando a uma metamorfose humana-animal. Ao que parece a satisfação pelo prazer não encontra limitações na ordem natural, em resposta a uma repressão que leva a um tipo de compulsão.

Atualmente, ao pesquisar por imagens que transitam nessa relação, é possível encontrar uma profusão de fotografias, imagem manipuladas digitalmente, ilustrações, desenhos, pinturas, esculturas, enfim, um sem número de elementos que exploram essa conexão proveniente da cultura oriental, sobretudo asiática.

É bem verdade que a influencia oriental, de um modo mais amplo, já é antiga e consolidada na arte ocidental. Portanto, como colocado a pouco, para além de uma referência oriental, associada a uma lenda, trago o aspecto do inconsciente coletivo para fazer uma analogia da frequente associação e fascinação do tentáculo como órgão fálico.

Há uma afeição do lado masculino pela fantasia da multi-penetração, superando os limites fisiológicos, no intuito de satisfazer de maneira solo e sublime o que somente mais de um parceiro poderia fazer. Este ser "onipresente" pode satisfazer as zonas erógenas de sua 


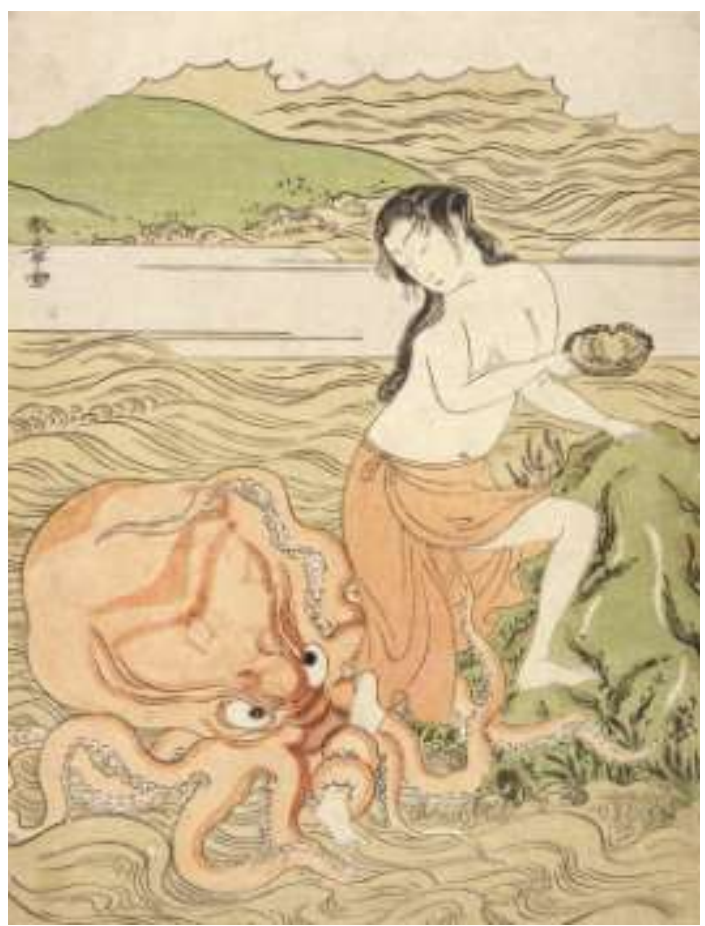

Fig. 7 - Katsukawa Shunshō (1726-1792), Abalone Fishergirl with an Octopus, c.1773-1774. xilogravura, 25,08 x 19,05 cm

(Fonte: http://collections.lacma.org/node/207959)

Poiésis, Niterói, v. 18, n. 30, dez. 2017. 


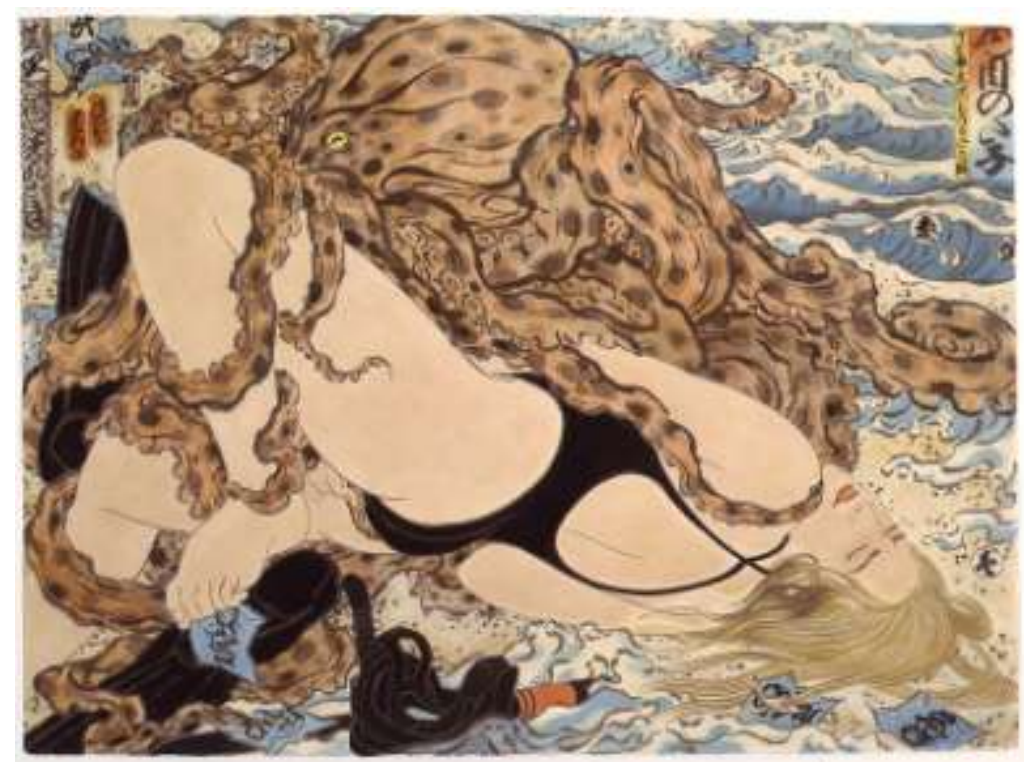

Fig. 8 - Masami Teraoka (1936 -), New Wave Series, Sarah and Writhing Octopus, 1992. aquarela sobre papel, $57,8 \times 76,2 \mathrm{~cm}$

(Fonte: http://masamiteraoka.com/archive/early_work.html)

Poiésis, Niterói, v. 18, n. 30, dez. 2017. 
parceira de maneira simultânea, atando-a num sexo selvagem, dominador, primitivo, lascivo. A palavra "striped" acaba virando um jogo polissêmico, pois facilmente poderia ser substituída por estupro.

Em Striped VI (Fig. 9), a jovem figura feminina está coberta com um tecido, mas partes do tronco e das pernas estão à mostra. Parece que ela foi usada e descartada. A pintura recebe um tratamento "sujo" de aquarela que remete ao ambiente sórdido da qual ela faz parte, a exemplo dos desenhos anteriores, porém, de certa forma, a jovem e a criatura mesclam-se harmoniosamente com fundo branco quando se integram através do esmaecimento que a aguada ocasiona. Alguns feixes brancos tendem a abrir um espaço luminoso sobre o desenho, potenciando o aspecto para além do sujo: a imagem também parece gasta, usada em tons neutros, próxima à monocromia.

É nesse sentido que a jovem se apresenta: usada e reusada a ponto de se desgastar. A mancha escura que delineia os olhos, aqui aparece mais regular e menos visceral. As madeixas tentaculares, provenientes da criatura abissal, recaem sobre os ombros delicadamente no intuito de seduzi-la numa espécie de quimera, que se desdobra por toda a composição, transformando-a em uma aparição, em um vislumbre anímico. A moça despida sob o tecido e as faixas escorridas fazem jus ao termo striped: mais do que tirar a roupa, ela foi despida de sua dignidade, todavia os braços contra o corpo retém algo que talvez não tenha se perdido, pois parece esconder a vergonha.

Insisto na ideia de que o polvo é a criatura que insurge como o parasita abissal. É o próprio mal encarnado que ludibria com seus tentáculos e entorpece os seus hospedeiros, enredando-os sob a personificação de uma força anamórfica, de um monstro, contra o qual lutamos ou nos deixamos vencer.

Como propõe Calabrese (1987), o monstro contemporâneo é um ser entrópico, o qual configura diversas formas e funções, sem necessariamente demonstrar características boas ou ruins. Apenas se beneficia ao se estabilizar sobre um hospedeiro através de uma relação de prazer e dano. Sendo assim, o polvo é um agente, submerso e emerso: ora

Poiésis, Niterói, v. 18, n. 30, dez. 2017. 
Fig. 9 - Rafael Coutinho, Striped VI, 2016.

grafite e aquarela sobre papel, $21 \times 29,5 \mathrm{~cm}$

(Fonte: Acervo pessoal, Campinas, SP)

Poiésis, Niterói, v. 18, n. 30, dez. 2017. 
aparece, ora se esconde; ora se expande, ora se contrai. Numa espécie de continuidade da lenda de Taishokan: ao invés da mergulhadora ser morta pela criatura tendo por motivo uma pérola, nos meus desenhos a criatura estabeleceu um vínculo, uma relação de simbiose com a mulher, que se tornou algo de maior valor para a criatura. Sendo assim, as mulheres representadas em Corpos Striped são cativas, impedidas de retornar à superfície, caladas ou cegas por um estanque negro.

A mulher de Striped IX (Fig. 10) apresenta uma proximidade com a fotografia publicitária, tendo em vista o caráter ensaístico e até mesmo sensual da imagem. A figura vangloriase de sua beleza efêmera, traduzida no desgaste da aguada de aquarela, prenunciando o final desta relação prazerosa, porém danosa. Danosa porque são reprimidas por uma sociedade que ainda denuncia a busca pelo prazer por parte das mulheres, pois são vistas como objetos que proporcionam a satisfação. Portanto, de uma maneira generalizada, a sociedade obriga a mulher a conviver com esse monstro, incrustado perante uma sociedade predominantemente machista, sendo que deveria haver equilíbrio de forças.

Em uma visão machista, a produção midiática do prazer está voltada para a subjugação da mulher como objeto de prazer, que pode ser alimentada com dinheiro, recursos, carros, casas, em suma, uma vida de ostentação e entregue à luxúria. Afinal, não foi isto o que a mergulhadora da lenda de Taishokan foi buscar no abismo? Ao tentar recuperar a pedra preciosa visando o bem de seu filho, não ficou pelo caminho, enredada, amordaçada, ludibriada e extasiada de dor e prazer?

As mulheres presentes em Corpos Striped tipificam as mulheres contemporâneas, inseridas em um contexto social repressor, as quais sacrificam seus corpos, calam as suas vozes e fecham os seus olhos para se ausentarem como testemunhas sob a pena de serem mortas ou dadas como desaparecidas, diante de uma sociedade absurda que, fomenta a ilusão de valorizar mais a forma do que a substância.

Poiésis, Niterói, v. 18, n. 30, dez. 2017. 
Fig. 10 - Rafael Coutinho, Striped IX, 2016.

grafite e aquarela sobre papel, $21 \times 29,5 \mathrm{~cm}$

(Fonte: Acervo pessoal, Campinas, SP)

Poiésis, Niterói, v. 18, n. 30, dez. 2017. 


\section{Notas}

' A simbiose, termo criado por Heinrich Anton De Bary em 1879, é caracterizada pela associação entre dois ou mais organismos de espécies diferentes, a qual pode ser permanente ou de longa duração. Os organismos envolvidos na simbiose podem sofrer benefícios ou prejuízos e, ainda, simplesmente não serem afetados durante a associação. (DE BARY apud PARACER; AHMADJIAN, 2000, p. 6, tradução nossa).

ii Taishokan é uma lenda medieval, suas muitas variantes combinam elementos da mitologia japonesa. Sua representatividade pode ser vista em pinturas e gravuras de origem japonesa. (Fonte: The Art Institute of Chicago. http://www.artic.edu/aic/collections/exhibitions/BeyondGoldenClouds/ artwork/145673).

\section{Referências}

CALABRESE, Omar. A idade neobarroca. Lisboa: Edições 70, 1987.

JUNG, Carl Gustav. O homem e seus símbolos. Rio de Janeiro: Nova Fronteira, 2008.

PARACER, Suridar; AHMADJIAN, Vernon. Symbiosis: An Introduction to Biological Associations. Nova York: Oxford University Press, 2000.

STRAMBI, Marta Luiza. Cria Cuervos. Uma aproximação com a fotografia de Carmen Calvo. Anais do Intercom - Sociedade Brasileira de Estudos Interdisciplinares da Comunicação, XXXI Congresso Brasileiro de Ciências da Comunicação, Natal, RN, 2 a 6 de setembro de 2008. Disponível em http://www.intercom.org.br/papers/nacionais/2008/resumos/R31325- 1.pdf. Acesso em 8/5/2016. 